\title{
Jörg Fisch
}

\section{Selbstbestimmung vor der Selbstbestimmung}

\author{
Die Herausbildung des modernen Begriffs des \\ Selbstbestimmungsrechts der Völker in Amerika
}

\section{Die Entstehung des Begriffs, Selbstbestimmungsrecht der Völker}

Begriffe haben, paradox gesprochen, in der Regel eine vorbegriffliche Phase. In ihr ist der Sachverhalt, der durch einen Begriffsausdruck zusammengefaßt wird, bereits als Einheit bewußt, während die prägnante sprachliche Bezeichnung noch fehlt ${ }^{1}$. Zuweilen ist aber auch der Ausdruck zuerst, und er wird nur langsam inhaltlich ausgefüllt, also terminologisch gestaltet.

Einen besonders ausgeprägten Fall einer späten Entstehung und noch späteren Ausbreitung eines Begriffswortes im Vergleich zu dem mit ihm gedachten Sachverhalt bildet der Begriff der (kollektiven) Selbstbestimmung eines Volkes, prägnant dann als Selbstbestimmungsrecht der Völker. Der Ausdruck ist vermutlich erst in den frühen 1850er Jahren mehr beiläufig entstanden. So sprach der ungarische Politiker Lajos Kossuth am 3. November 1851 in London vom „souveränen Recht jeder Nation, über sich selbst zu bestimmen“ („sovereign right of every nation to dispose of itself“). Das sei ein „allgemeines Gesetz der Menschheit“ („common law of mankind“), meinte er am 11. Dezember des gleichen Jahres in New York². Geläufiger wurde die Wendung erst seit den 1860er Jahren. J. H. Guigné sprach 1862 vom „Recht der Völker, über sich selbst zu bestimmen“ („droit des peuples de disposer d'eux-mêmes“) ${ }^{3}$, und 1865 beschäftigte sich die Erste Internationale in London mit dem „Recht jedes Volkes, über sich selbst zu bestim-

$1 \mathrm{Zu}$ dieser und weiteren im folgenden verwendeten Unterscheidungen s. Jörg Fisch: Zusammengesetzte Begriffe, in: Archiv für Begriffsgeschichte 17 (1973) 93-118.

2 Lajos Kossuth: Selected speeches. Condensed and abridged, with Kossuth's express sanction, by Frances W. Newman (New York 1854) 15, 50 u. ö. Kossuth hielt seine Vorträge auf Englisch. Ob er ursprünglich englisch oder ungarisch formulierte, ließ sich nicht klären. Vgl. noch die ähnliche Formulierung von 1852 in: Kossuth in New England. A full account of the Hungarian governor's visit to Massachusetts (Cleveland 1852) 157. Frühere Belege, insbesondere auch für die Revolutionen 1848/1849, sind bislang nicht beigebracht worden.

3 J. H. Guigné, Considérations sur l'Italie (Paris 1862) 67. 
men“ („right of every people to dispose of itself“)4. Auch im Deutschen kam der Ausdruck ab den frühen 1860er Jahren auf; die eigentliche Formel findet sich besonders prägnant 1870 beim Philosophiehistoriker Eduard Zeller als „Selbstbestimmungsrecht der Völker" 5 .

Die Rede von einer vorbegrifflichen Phase eines Begriffs ist insofern problematisch, als ein klares Kriterium fehlt, mit dessen Hilfe der Zeitpunkt der Entstehung eines Begriffs bestimmt werden kann. Das gilt auch und besonders für ,Selbstbestimmung' und ,Selbstbestimmungsrecht'. Die Suche nach einzelnen Elementen eines Begriffs führt leicht zum Postulat eines Universalbegriffs, daß also etwa (kollektive, auf Völker oder Staaten bezogene) Selbstbestimmung zu allen Zeiten und an allen Orten vorkommt, im Sinne der in Bürger- und Sezessionskriegen geforderten und erkämpften Unabhängigkeit, vom jüdischen Kampf gegen die Römer über den Abfall der Niederlande von Spanien, den Aufstand von Tupac Amaru in Peru und den US-Bürgerkrieg bis zu den Auseinandersetzungen zwischen Serben und Kosovaren am Ende des 20. und zu Beginn des 21. Jahrhunderts. Die Antwort auf die Frage, ob man von einem weltgeschichtlichen Universal oder einem spezifischen, beispielsweise nur für die europäische Neuzeit geltenden Epochenbegriff sprechen will, hängt letztlich von der gewählten Definition ab. Hier soll die (stets kollektiv verstandene) Selbstbestimmung als historischer, erst seit dem späten 18. Jahrhundert aufkommender Begriff betrachtet werden, wobei besonderes Augenmerk auf eine vorbegriffliche Phase gelegt wird. Diese Phase zeigt, wenn eine entsprechende Definition verwendet wird, einige Eigentümlichkeiten, die sonst bei der Entstehung eines Begriffs zumindest nicht in dieser Deutlichkeit sichtbar werden. Selbstbestimmung und Selbstbestimmungsrecht finden sich in Amerika im späten 18. und im frühen 19. Jahrhundert von der Sache her gesehen in voller Ausprägung, ohne daß der entsprechende Ausdruck auch nur in Ansätzen gebildet wird. Wohl aber ist eine Art Vorläuferbezeichnung weit verbreitet: ,Unabhängigkeit‘. In der zweiten Hälfte des 19. Jahrhunderts entsteht dann der Ausdruck ,Selbstbestimmung(srecht) ${ }^{\varsigma}$ - aber nicht etwa in Amerika, wo die Sache schon lange existiert, sondern in Europa. Er wird zunächst nur selten gebraucht, gegen Ende des Ersten Weltkrieges aber plötzlich zu einem zentralen, exklusiv positiv verstandenen politischen Schlagwort. Ein solches ist er seither geblieben. Seit der Mitte des 20. Jahrhunderts ist er darüber hinaus zu einem der wichtigsten Begriffe des Völkerrechts geworden, indem ein kollektiv aufgefaßtes Recht aller Völker auf Selbstbestimmung kodifiziert worden ist ${ }^{6}$. Doch

${ }^{4}$ Minutes of London Conference of the First International, September 1865, in: Documents of the First International, hrsg. v. Institute of Marxism-Leninism of the CC, CPSU 1 (Moskau o.J.) 246.

5 Eduard Zeller, Das Recht der Nationalität und die freie Selbstbestimmung der Völker, in: Preussische Jahrbücher 26 (1870) 627-650, hier 628. Vgl. Luigi Emery, „Selbstbestimmungsrecht" (per la storia di una formula), in: Rivista internazionale di filosofia del diritto 18 (1938) 312-323.

6 19. Dezember 1966: Internationaler Pakt über bürgerliche und politische Rechte und Internationaler Pakt über wirtschaftliche, soziale und kulturelle Rechte, in: Menschenrechte. Ihr internationaler Schutz, hrsg. v. Bruno Simma (München ${ }^{21985)} 22-38$ und 60-68. In bei- 
bis heute wird die vorbegriffliche Phase, die sich wesentlich in Amerika abgespielt hat, nicht als Teil der Geschichte des Begriffs (die weitgehend auf Europa, Afrika und Teile Asiens reduziert worden ist) erkannt oder gar anerkannt. Die Terminologie von ,Selbstbestimmung' und ,Selbstbestimmungsrecht' wird nach wie vor so gut wie gar nicht auf die Loslösung Amerikas von Europa bezogen. Es ist die These der folgenden Ausführungen, daß ,Selbstbestimmung' und ,Selbstbestimmungsrecht' seit dem späten 18. Jahrhundert begriffsprägende Kraft gehabt haben, obwohl sie im terminologischen Sinne zunächst gar nicht vorhanden waren und, als sie dann ab der zweiten Hälfte des 19. Jahrhunderts zur Verfügung standen, auch noch nachträglich konsequent vom Bezug auf ihre Entstehungsphase ferngehalten wurden. Das Selbstbestimmungsrecht der Völker hat also eine entscheidende amerikanische Entstehungsphase, die bislang weitgehend ignoriert worden ist. Am Schluß ist zu fragen, weshalb der Begriff nach seiner Entstehung nicht auf diese Phase zurückprojiziert worden ist.

\section{Definitionen: absolute und konditionale Rechte}

Die hier verwendete Definition der Selbstbestimmung und des Selbstbestimmungsrechts geht von zwei Elementen aus, die sich gegenseitig ergänzen und verstärken, einem faktischen und einem rechtlichen. Nur wenn beide gegeben sind, soll von Selbstbestimmung und Selbstbestimmungsrecht die Rede sein.

1. Das faktische Element bezieht sich auf die Entkolonisierung. Von Selbstbestimmung, auch wenn der Ausdruck nicht vorkommt, soll hier nur dann die Rede sein, wenn ein Gebiet, das von einem anderen Gebiet aus beherrscht wird, von dem es entweder durch ein Meer oder durch eine größere Landmasse (oder auch durch beides), klar abgetrennt ist, die politische Selbständigkeit oder das Recht darauf erlangt. Dieses Kriterium ist restriktiver als der moderne Selbstbestimmungsbegriff, bei dem man auch dann von Selbstbestimmung spricht, wenn ein Gebiet sich selbständig macht oder in die Unabhängigkeit entlassen wird, das vorher mit einem oder mehreren anderen auf einer zusammenhängenden Landmasse einen Staat bildete. Das gilt bis zur Gegenwart und ist bei der Auflösung der Sowjetunion und Jugoslawiens, aber auch etwa der Tschechoslowakei, deutlich geworden. Andererseits ist nicht erst heute, sondern mindestens seit dem USamerikanischen Bürgerkrieg heftig umstritten, ob eine Sezession als zulässig zu gelten hat. Jedenfalls verliert der Selbstbestimmungsbegriff seine historische Tiefenschärfe, wenn jegliche politische Loslösung eines Gebietsteils, die in der Geschichte vorgekommen ist, als Resultat von oder als Akt der Selbstbestimmung betrachtet wird. Solange eine solche Verselbständigung nicht in den Quellen ausdrücklich als Selbstbestimmung bezeichnet wird, gilt im folgenden nur die Ent-

den Pakten lautet Art. 1,1 identisch: „Alle Völker haben das Recht auf Selbstbestimmung. Kraft dieses Rechts entscheiden sie frei über ihren politischen Status und gestalten in Freiheit ihre wirtschaftliche, soziale und kulturelle Entwicklung" (ebd. 22; 60). 
kolonisierung über eine größere Distanz hinweg als Auswirkung von oder als Akt der Selbstbestimmung.

2. Wichtiger ist das rechtliche Kriterium. Von Selbstbestimmung soll hier nur dann die Rede sein, wenn sie als Ausübung eines absoluten und nicht nur eines konditionalen Rechts eines Volkes oder einer Gruppe, die sich selbst als Volk oder als Teil eines Volkes versteht, auf Unabhängigkeit erscheint. Ein absolutes Recht steht einem Berechtigten kraft dessen bloßer Existenz zu, solange er es nicht durch eigenes Unrecht verwirkt hat und es nicht am gleichen Recht Anderer seine Grenzen findet. Im Falle des Selbstbestimmungsrechts der Völker heißt das, daß ein Volk, in Übereinstimmung mit den Internationalen Menschenrechtspakten von 1966, einfach aufgrund seiner Eigenschaft, ein Volk zu sein, oder sich als ein solches zu verstehen, das Recht auf Selbstbestimmung und damit auf die Bildung eines eigenen, unabhängigen Staates hat. Weitere Bedingungen müssen nicht erfüllt sein. Der Grund für ein solches Recht liegt ausschließlich in dessen Inhaber, nicht in demjenigen, auf dessen Kosten es gewährt wird. Der Gewährende kann sich verhalten, wie er will - er hat keinen Einfluß auf das Recht des Begünstigten. Ein konditionales Recht hingegen ist an zusätzliche Bedingungen geknüpft, die nicht vom Berechtigten, sondern vom Verpflichteten erfüllt werden müssen. Im vorliegenden Falle bedeutet das in der Regel: Nur wenn ein Staat ein Volk oder einen Volksteil oder eine Minderheit schlecht behandelt, erhält der schlecht Behandelte ein Recht auf Unabhängigkeit, und selbst in diesem Falle nur dann, wenn jener sich weigert, Genugtuung zu leisten, als ein Mittel zur Abhilfe bei schlechter Behandlung des Berechtigten durch den Verpflichteten, also bei Tyrannei, Despotismus oder ungerechter Regierung. Es handelt sich um ein Notrecht, das den Berechtigten vor Unrecht schützen soll. Man kann auch von einem remedialen Recht sprechen ${ }^{7}$.

\section{Die Unabhängigkeit der Vereinigten Staaten}

Ab welchem Zeitpunkt kann und muß gemäß diesen Kriterien von Selbstbestimmung und einem Selbstbestimmungsrecht gesprochen werden? Beim faktischen Kriterium liegt die Sache klar: Die erste Entkolonisierung von weltgeschichtlicher Bedeutung ist die Unabhängigkeit der USA, eingeleitet durch die Unabhängigkeitserklärung von 1776 und die Anerkennung dieser Unabhängigkeit durch Frankreich 1778 und durch Großbritannien 1783.

Schwieriger fällt die Entscheidung beim rechtlichen Kriterium. Hier erfolgt ein allmählicher Übergang, kann nicht von einer scharfen Grenze die Rede sein. Im-

7 Das Konzept eines remedialen Rechts im Zusammenhang der Sezession ist insbesondere von Allen Buchanan entwickelt worden. Vgl. vor allem Allen Buchanan, Secession. The morality of political divorce from Fort Sumter to Lithuania and Quebec (Boulder 1991) und ders., Justice, legitimacy, and self-determination. Moral foundations for international law (Oxford 2004). 
merhin ist gemäß diesem Kriterium die US-Unabhängigkeitserklärung noch keine Ausübung eines Selbstbestimmungsrechts. Auch wenn in der Wirkungsgeschichte der Anfang der Unabhängigkeitserklärung mit seiner Berufung auf ewige Wahrheiten und unveräußerliche Rechte am wichtigsten gewesen ist, so ist die Stoßrichtung des Texts insgesamt eine andere, ausgesprochen traditionalistische. Im Mittelpunkt steht die ausführliche Aufzählung des vom englischen König Georg III. begangenen Unrechts. Die Liste enthält auch vergleichsweise harmlose Vorwürfe, solche jedenfalls, die kaum einen Krieg zu rechtfertigen vermögen, etwa die Erschwerung der Einwanderung oder die Einstellung zu vieler Beamten'.

Der Zweck der Anschuldigungen, die etwa die Hälfte des Texts ausmachen, ist klar: Sie sollen den König ins Unrecht setzen und die amerikanischen Forderungen rechtfertigen: „Ein Fürst, dessen Charakter auf solche Weise durch lauter Handlungen gekennzeichnet ist, die einen Tyrannen ausmachen, ist nicht geeignet, über ein freies Volk zu herrschen. “9 Das heißt umgekehrt: Hätte sich der König korrekt verhalten, hätte er seine Pflichten erfüllt, so hätten die Amerikaner keinen Grund zur Aufkündigung ihrer Gefolgschaft (allegiance). Erst die permanenten Rechtsverletzungen, die den König zum Despoten und Tyrannen abstempeln, und seine Weigerung, Abhilfe zu schaffen, geben den Amerikanern das Recht, die Unabhängigkeit zu proklamieren. Ihr Recht auf Unabhängigkeit ist also lediglich konditional. Solange sie gut regiert wurden, hatten sie offenbar kein Recht, sich ihrer Regierung zu entziehen oder zu entledigen. In dieser Hinsicht ist das Vorgehen der Amerikaner durchaus traditionell. Sie berufen sich nicht auf irgendein neues Recht, sondern auf das Recht des Widerstands gegen eine tyrannische Herrschaft, das innerhalb und außerhalb Europas Tradition hat, ein Recht, das bei jedem Aufstand, jeder Rebellion und Revolution in Anspruch genommen werden kann ${ }^{10}$. Es ist kein Recht, das nach Belieben, unabhängig vom Verhalten der Gegenseite ausgeübt werden kann. Vielmehr muß es zuerst durch Unrecht der Gegenseite aktiviert werden. Erst wenn die Herrschenden die Rechte der Beherrschten verletzt haben, haben diese ein Recht auf Widerstand.

Noch fehlt also das absolute Recht. Damit kann nach den hier verwendeten Kriterien auch nicht im umfassenden Sinne von Selbstbestimmung und Selbstbestimmungsrecht gesprochen werden. Die Erlangung der Unabhängigkeit ist die Entschädigung für erlittenes Unrecht, nicht die Inanspruchnahme eines Rechts, das dem Berechtigten unabhängig vom Verhalten des Verpflichteten zukommt.

8 Die Unabhängigkeitserklärung wird hier und im folgenden zitiert nach Henry Steele Commager (Hrsg.), Documents of American history (New York 91973) 1, $100 \mathrm{ff}$. Für eine Einordnung in universalgeschichtliche Zusammenhänge vgl. David Armitage, The Declaration of Independence. A global history (Cambridge, Mass. 2007).

9 "A Prince, whose character is thus marked by every act which may define a Tyrant, is unfit to be the ruler of a free People." Commager, 1, 102.

10 Zum Forschungsstand vgl. etwa Robert von Friedeburg (Hrsg.), Widerstandsrecht in der frühen Neuzeit. Erträge und Perspektive der Forschung im deutsch-britischen Vergleich (Berlin 2001); ders, Art. Widerstandsrecht, in: Historisches Wörterbuch der Philosophie 11 (Darmstadt 2004) 714-720; Jean-Claude Zancarini (Hrsg.), Le droit de résistance, XIIeXXe siècle (Lyon 2001). 
Immerhin finden sich in der Unabhängigkeitserklärung und in ihrem Umkreis doch schon einige Ansätze, die zeigen, in welche Richtung die weitere Entwicklung verlaufen wird.

Gleich zu Beginn der Unabhängigkeitserklärung ist davon die Rede, es könne für ein Volk nötig werden, die politischen Bande zu einem andern Volk aufzulösen und unter den Mächten der Welt „die getrennte und gleichberechtigte (separate and equal) Stellung einzunehmen, zu der die Gesetze der Natur und des Gottes dieser Natur sie ermächtigen “. Hier wird eine grundsätzliche Gleichheit nicht nur der Staaten, sondern der Völker postuliert, und man könnte von einem Recht auf eine solche gleichberechtigte Stellung sprechen. Doch davon ist nicht wirklich die Rede. Denn schon ganz zu Beginn heißt es: „Wenn es im Lauf der menschlichen Dinge nötig wird für ein Volk, die politischen Bande aufzulösen, die es mit einem anderen verbunden haben“ und nicht etwa, wenn dieses Volk das Bedürfnis empfindet, das entsprechende Recht in Anspruch zu nehmen. Das gilt auch wieder am Schluß, wenn es heißt, „daß diese Vereinigten Kolonien freie und unabhängige Staaten sind und rechtmäßigerweise sein sollen“. Dieser Aussage liegt nicht ein angenommenes uneingeschränktes Recht auf Unabhängigkeit zugrunde, sondern es geht erneut um die Folgen der Rechtsverletzungen durch die Gegenseite. Die Vorstellung, sich einfach auf ein absolutes Recht auf Unabhängigkeit zu berufen, ohne zu begründen, weshalb ein so außerordentlicher Schritt getan wurde, lag den Unterzeichnern der Erklärung fern. So sagen sie denn auch ausdrücklich, daß Rücksicht auf die Meinungen der Menschen es gebiete, die Gründe für die Lossagung vom bisherigen Herrn anzugeben. Ziel der Erklärung ist der Nachweis, daß Rechte, die noch überwiegend feudaler Natur sind, indem der König als Lehnsherr und die Kolonien als Vasallen gegenseitige, wenn auch ungleiche Rechte und Pflichten haben, verletzt worden sind und nicht, daß die Kolonisten ein uneingeschränktes Recht auf Unabhängigkeit haben.

\section{Thomas Paine und das Recht auf Unabhängigkeit}

Nun wurde in einer solchen Erklärung sicherlich mit besonderer Vorsicht argumentiert. Doch auch in anderen Zusammenhängen wurde kein uneingeschränktes, nichtkonditionales Recht auf Unabhängigkeit postuliert ${ }^{11}$. Das wird besonders deutlich im erfolgreichsten und wohl auch einflußreichsten Pamphlet im Zusammenhang des nordamerikanischen Unabhängigkeitskampfes, dem Traktat Common Sense von Thomas Paine, der im Januar 1776 erschien ${ }^{12}$. Paine trug die Argumente zugunsten der Unabhängigkeit zusammen. Neben der Betonung des

11 Vgl. zum Folgenden Edwin G. Burrows, Michael Wallace, The American revolution: the ideology and psychology of national liberation, in: Perspectives in American History 6 (1972) 165-306.

12 Thomas Paine, Common Sense, in: Michael Foot, Isaac Kramnick (Hrsg.), Thomas Paine Reader (Harmondsworth 1987) 65-115. Im folgenden wird nach dieser Ausgabe zitiert. 
Unrechts der Gegenseite standen vor allem Hinweise auf die Unvermeidlichkeit einer Emanzipation. Dazu diente etwa der Vergleich mit den menschlichen Lebensaltern: was Kindern gegenüber gerechtfertigt war, war es nicht mehr gegenüber Erwachsenen ${ }^{13}$. Auch künftig wichtig wurde das geographische Argument, daß sich ein Land nicht über tausende Kilometer Ozean hinweg regieren lasse und $\mathrm{daß}$ es hochgradig absurd sei anzunehmen, ein Kontinent lasse sich auf ewig durch eine Insel beherrschen ${ }^{14}$. Auch die Reifemetapher lag auf der Hand: Der Kontinent ist jetzt reif für die Unabhängigkeit ${ }^{15}$. Weiter bemüht Paine das Naturrecht: „Eine eigene Regierung ist unser natürliches Recht." 16 Hier kommt er dem absoluten Recht, dem Selbstbestimmungsrecht am nächsten. Aber ein Anspruch auf Unabhängigkeit wird dann doch nicht daraus abgeleitet. Paine zieht keine weiteren Konsequenzen - die Grundlage bleibt das Unrecht der Gegenseite. Offensichtlich schreckt Paine vor dem letzten Schritt zum absoluten Recht zurück. So gibt er sich überzeugt, Amerika hätte ohne Kolonialherrschaft ganz anders floriert ${ }^{17}$. Hier läge die Forderung nach einem Recht auf Unabhängigkeit nahe - aber es wird nicht postuliert. Das Argument bleibt empirisch: Eine unabhängige Kolonie gedeiht besser als eine abhängige. Daraus werden keine rechtlichen Folgen abgeleitet. Wer die Unabhängigkeit gut zu nutzen versteht, hat deshalb noch lange kein Recht auf Unabhängigkeit.

Das beste Argument gegen die Zurückhaltung, die selbst Paine in der Frage eines absoluten Rechts auf Unabhängigkeit noch bestimmte, war die Unabhängigkeitserklärung selber, und vor allem ihr Erfolg. Spätestens im Januar 1777 zog Paine die Konsequenzen daraus, wobei er auch gleich umfassend kontinental argumentierte: Er sprach vom „natürlichen Recht des Kontinents auf Unabhängigkeit“. Seine zögernde Haltung vom vorangegangenen Jahr vergessend, behauptete er jetzt, dies sei „ein Punkt, der noch niemals in Frage gestellt wurde. Er erlaubt keinerlei Diskussion. Ein solches Recht zu leugnen wäre eine Art Atheismus gegen die Natur“18.

\section{Die Konstruktion des Selbstbestimmungsrechts in Hispanoamerika}

Die Unabhängigkeitserklärung der USA war so erfolgreich, daß sie in der gleichen Region kein zweites Mal eingesetzt zu werden brauchte. Nach dem Friedensschluß von 1783 stand das Existenzrecht des neuen Staates nicht mehr ernsthaft

13 Ebd. 80 f.; 89.

14 Ebd. 86.

15 Ebd. 94.

16 Ebd. 92.

17 Ebd. 81.

18 Thomas Paine, The American crisis III (19. April 1777), in: ders., Collected writings, hrsg.

v. Eric Foner (New York 1995) 116-146, hier 121. 
zur Debatte. So mußte auch die legitimatorische Grundlage der Erklärung von 1776 nicht erweitert werden. Es erstaunt infolgedessen nicht, daß die weitere Entwicklung des Begriffs in einem anderen, aber doch verwandten Zusammenhang erfolgte, in der Entkolonisierung Lateinamerikas, die überwiegend in die Jahre zwischen 1808 und 1826 fiel ${ }^{19}$. Auch wenn heute angesichts der unterschiedlichen Ergebnisse der beiden Unabhängigkeitsprozesse in Nord und Süd eher die - keineswegs zu leugnenden - Differenzen betont werden, so war der Einfluß der Emanzipation der nordamerikanischen Kolonien auf den Süden zeitgenössisch außerordentlich groß. Die Vereinigten Staaten wurden in den meisten Punkten, die die Loslösung vom europäischen Mutterland betrafen, zum bewunderten Vorbild. Auch das Konzept eines Rechts auf Selbstbestimmung scheint, wie Paine zeigt, im Norden entstanden zu sein. Aber es gelangte erst im Süden in die entscheidenden Dokumente, also die Unabhängigkeitserklärungen. Im Norden hatte die Unabhängigkeitserklärung ja kein Selbstbestimmungsrecht gekannt, sondern lediglich ein traditionelles Widerstandsrecht. Noch nicht einmal von ,Unabhängigkeit' war die Rede ${ }^{20}$, und das Dokument bezeichnete sich selbst lediglich als „Declaration“, nicht als „Declaration of Independence“. In den hispanoamerikanischen Erklärungen hingegen war sehr oft von ,Unabhängigkeit‘ die Rede ${ }^{21}$. Die in der französischen Tradition stehende erste amerikanische Unabhängigkeitserklärung nach 1776, 1804 in Haiti, ist zwar von extremem Haß auf die als Barbaren denunzierten Franzosen geprägt. Sie stellt sich unter das Motto „Freiheit oder Tod“; jeder Franzose, der ins Land kommt, soll umgebracht werden. Dazu ist ,Unabhängigkeit‘ zum zentralen Begriff geworden. Von einem Recht darauf aber ist nicht die Rede 22 .

Wichtiger noch waren die staatsrechtlichen Unterschiede. Im Norden war der eigene, englische König, der seine Macht unrechtmäßig vergrößern wollte oder

19 Als Überblick John Lynch: The Spanish American revolutions 1808-1826 (London 1973). Vgl. auch Inge Buisson, Herbert Schottelius, Die Unabhängigkeitsbewegungen in Lateinamerika 1788-1826 (Stuttgart 1980); John Lynch (Hrsg.), Latin American Revolutions, 18081826. Old and new world origins (Norman, Okl. 1994); Jaime E. Rodriguez, La independencia de la América española (Mexiko 2005); Manuel Chust, José A. Serrano (Hrsg.), Debates sobre las independencias iberoamericanas (Madrid 2007). Eine Zwischenstellung zwischen Nord und Süd nehmen die verschlungenen Vorgänge auf Saint-Domingue/Haiti seit 1789 ein. Sie werden hier nicht gesondert betrachtet. Sie sind zwar von besonderer Bedeutung für die Geschichte der Sklaverei, zeigen aber keine wirkliche Sonderentwicklung in der hier interessierenden Frage.

Die Unabhängigkeitskämpfe in ganz Amerika 1775-1826 werden hier als erste Entkolonisierung bezeichnet, im Gegensatz zur zweiten, weltweiten im 20. Jahrhundert.

20 Nur das Adjektiv erscheint, im berühmten Satz ,that these United Colonies are, and of Right ought to be Free and Independent States“. Am Ende ist dann nochmals von „Independent States" die Rede. Selbst die Unabhängigkeit ist also noch nicht zum Begriff geronnen. Commager, (s. Anm. 8) 1, 102.

21 Eine Zusammenstellung der meisten amerikanischen Unabhängigkeitserklärungen des 18.-20. Jahrhunderts findet sich bei Javier Malagón (Hrsg.), Las actas de independencia de America (Washington 21973).

22 1. Januar 1804 Haiti. Ebd. 75-78. 
zumindest zu wollen schien, der Hauptfeind, gegen den das Widerstandsrecht mobilisiert werden mußte und konnte. In Iberoamerika hieß der Hauptfeind bis 1814 Napoleon. Für die Kolonien ging es, als Napoleon 1807/1808 die Iberische Halbinsel eroberte, zunächst nicht um den Abfall vom eigenen König, sondern um dessen Unterstützung gegen den französischen Usurpator. Die 1807 erfolgte französische Besetzung Portugals hatte zur Flucht der Königsfamilie und des Hofes nach Brasilien geführt, während Napoleon 1808 in Spanien den rechtmäßigen Herrscher zur Abdankung gezwungen und seinen eigenen Bruder Joseph Bonaparte an dessen Stelle gesetzt hatte. Die Kolonien stellten sich hinter die rechtmäßigen Herrscher, und ihre seit 1809 einsetzenden Unabhängigkeitserklärungen waren zunächst mehr eine Auswirkung des Machtvakuums als des Widerstands gegen den König. Angesichts der britischen Seeherrschaft war Napoleon nicht imstande, die spanischen Kolonien in Amerika zu beherrschen. Erst nach dem Ende der napoleonischen Kriege, als die spanische Krone versuchte, ihre absolutistische Stellung in den Kolonien zurückzugewinnen, wurde auch in Hispanoamerika der Unabhängigkeitskampf in erster Linie ein Kampf gegen die Krone. Jetzt bot sich, wie schon in den USA und auf Haiti, die tyrannische Herrschaft des Königs als Hauptargument für die Unabhängigkeit, die nun auch sehr häufig so bezeichnet wurde, in Anknüpfung an die Vorgänge im Norden geradezu an. Doch in der Zwischenzeit waren zusätzliche Begründungen aufgekommen. Die Stellung des spanischen Königs Ferdinand VII. war auch nach 1814 infolge seiner Absetzung und effektiven Machtlosigkeit unter Napoleon schwächer, als diejenige König Georgs III. 1775-1783 in Großbritannien und Nordamerika gewesen war. 1808-1814 war Ferdinand weder in Spanien noch in den Kolonien in der Lage gewesen, die Souveränität auszuüben. Nach spanischer Auffassung fiel diese dadurch an die lokalen Körperschaften, jedenfalls solange, bis wieder ein legitimer Herrscher an der Macht war ${ }^{23}$. Wollte er mehr als eine Galionsfigur sein, mußte er von den Kolonien anerkannt werden. Je mehr er versuchte, nach 1814 die alten Verhältnisse wiederherzustellen, umso hartnäckiger verweigerten die Kolonien die Anerkennung und riefen statt dessen die Unabhängigkeit aus. Bei der Rechtfertigung dieses Schritts insbesondere in den Unabhängigkeitserklärungen nahm die Verurteilung des Königs und seiner Regierung selbstverständlich einen zentralen Platz ein. Praktisch jede der zahlreichen Unabhängigkeitserklärungen (die zuweilen, nach Niederlagen, beim erneuten Versuch, die spanische Herrschaft abzuschütteln, wiederholt und zugleich neu formuliert wurden) wandte sich gegen die schlechte, tyrannische und ungerechte Herrschaft, die das Land während drei Jahrhunderten hatte erdulden müssen.

Doch diese Bemühung von $\mathrm{Haß}$ gegen den Herrscher und das Mutterland hielt sich im allgemeinen in Grenzen. Sie erreichte nicht die schrillen Töne und die

23 Vgl. Catalin Reyes, La ambigüedad entre lo antigo y lo nuevo. Dos mundos que se entrecruzan: Nueva Granada 1808-1810, in: Manuel Chust Calero (Hrsg.), Doceañismos e independencias: La constitución de 1812 y América (Madrid 2006) 99-120 und Inés Quintero, Lealtad, soberanía y representatividad en Hispanoamérica (1808-1811). Ebd. 121-139. 
Haßtiraden von Haiti oder den Umfang des schon geradezu pedantisch geführten Sündenregisters Georgs III. Meistens begnügte man sich mit einer pauschalen Verurteilung von drei Jahrhunderten Tyrannei. So hieß es 1818 in der chilenischen Erklärung: „Die Gewalt war die wichtigste Ursache dafür, daß sich die Neue Welt für mehr als dreihundert Jahre gezwungen sah, die Usurpation ihrer Rechte als Dogma zu betrachten und darin selber den Ursprung ihrer größten Aufgaben zu suchen."24 Sehr viel schärfer, und damit eher atypisch, fiel 1825 die Erklärung Boliviens aus: Der „iberische Löwe“ habe „während vieler Jahrhunderte den unglücklichen Körper Amerikas in Stücke gerissen und sich von seiner Substanz genährt“; darin zeige sich „die Wildheit jenes Monsters“25.

$\mathrm{Zu}$ einer Art Standardfigur wurde die Berufung auf die Rechte, die die neuen Staaten, nicht als Staaten, sondern als Völker, für sich zurückgewonnen hatten. Welche Art von Rechten es waren, wurde nicht gesagt. Doch es konnten keine vernünftigen Zweifel möglich sein, daß es um die Unabhängigkeit ging und damit um das Recht, einen eigenen Staat zu bilden, letztlich also um ein Selbstbestimmungsrecht, obwohl der Ausdruck anscheinend nie fiel. Immerhin betonten manche Erklärungen, das betreffende Volk wolle nach eigenem Geschmack handeln. Die Sache war klar; es fehlte nur der Begriff. 1816 meinten die Unterzeichner der argentinischen Erklärung einfach, sie wollten „die Rechte, die ihnen gestohlen wurden, zurückgewinnen“26. Immer wieder war von der „Zurückforderung der Rechte“ die Rede27. Solche Rückforderungen konnten sich auch gegen amerikanische Nachbarn richten, so etwa, als sich 1844 die Dominikanische Republik von Haiti lossagte ${ }^{28}$, und noch 1903, wenn auch sehr vorsichtig, bei der Sezession Panamas von Kolumbien ${ }^{29}$.

Andere Formeln sagten noch deutlicher, was gemeint war, indem sie die Freiheit betonten, letztlich die Freiheit, über sich selbst zu bestimmen. So sprach die bolivianische Erklärung 1825 von der „vollen Freiheit, über unser Schicksal zu bestimmen“30. Paraguay möchte 1842 „sich selbst gehören“31, und Venezuela betont schon 1811: „Wie alle Völker der Welt sind wir frei und befugt, von keiner anderen Autorität als unserer eigenen abzuhängen. “32

Die verschiedenen Typen von Argumenten werden am deutlichsten gebündelt in der sehr kurz gehaltenen mexikanischen Erklärung von 1821, von der hier etwas mehr als die Hälfte zitiert wird:

24 1. Januar 1818 Chile. Malagón, 50.

25 6. August 1825 Bolivien. Ebd. 22.

26 9. Juli 1816 Argentinien. Ebd. 6.

27 z. B. 5. Juli 1811 Venezuela. Ebd. 159; 1. Januar 1818 Chile. Ebd. 50; 26. August 1825 Uruguay. Ebd. 147.

28 16. Januar 1844 Dominikanische Republik. Ebd. 126.

29 4. November 1903 Panama. Ebd. 100.

30 6. August 1825 Bolivien. Ebd. 22.

31 25. November 1842 Paraguay. Ebd. 108.

32 5. Juli 1811 Venezuela. Ebd. 160. 
„Das mexikanische Volk [nación], das für dreihundert Jahre weder einen eigenen Willen noch den freien Gebrauch seiner Stimme gehabt hat, verläßt heute die Unterdrückung, in der es gelebt hat....

So ist dieser Teil des Nordens der Ausübung aller Rechte zurückgegeben, die ihm der Schöpfer der Natur verliehen hat, und die zivilisierten Völker [naciones cultas] des Landes erkennen diese Rolle als unveräußerbar und heilig an. Diese Völker haben die Freiheit, sich auf die ihnen am meisten zusagende Weise der Erlangung ihres Glücks zu konzentrieren, mit Vertretern, die ihren Willen und ihre Absichten sichtbar machen können. Das mexikanische Volk beginnt diese wertvollen Geschenke zu nutzen und erklärt feierlich, durch den Mund der obersten Regierung [Junta Suprema] des Reiches, daß Mexiko eine vom alten Spanien unabhängige und souveräne Nation [nación] ist. Es wird mit Spanien in Zukunft keine andere Verbindung pflegen als eine enge Freundschaft, gemäß den abgeschlossenen Verträgen. Es wird freundschaftliche Beziehungen mit den übrigen Mächten anknüpfen. “33

Vielleicht am nächsten kommt einer Forderung nach einem Selbstbestimmungsrecht ein Dekret der verfassunggebenden Nationalversammlung von Nicaragua, das 1823 von einem ,unerschütterlichen und unverjährbaren Recht der Völker, unserer Auftraggeber, auf ihre uneingeschränkte Freiheit und Unabhängigkeit" spricht ${ }^{34}$.

Außerhalb der Unabhängigkeitserklärungen wurden zusätzliche Argumente ins Spiel gebracht. Laut dem Mexikaner Bárcena hat jede Kolonie ein Recht auf Unabhängigkeit, das jederzeit verwirklicht werden darf: „Jede Kolonie bewahrt in ihrem Busen die Saat der Unabhängigkeit.“ Das sei ein "Gesetz der Natur" in jedem Lebewesen. Verzichte eine Kolonie zunächst darauf, „dann bleibt jedoch immer ihr Recht erhalten, davon Gebrauch zu machen, wenn es ihr gefällt“"35. Hier ist sicherlich von einem absoluten Recht auszugehen.

In dem Maße, in dem die Berufung auf ein uneingeschränktes Recht auf Eigenständigkeit und Unabhängigkeit an Gewicht gewann, verlor der Verweis auf königliches Unrecht an Bedeutung, denn letztlich war das Argument, ein Volk habe einfach nur schon qua Volk ein uneingeschränktes Recht auf Unabhängigkeit, stärker als die Berufung auf ein bloß konditionales, von Rechtsverletzungen des Königs abhängiges Recht, selbst wenn diese Rechtsverletzungen in den dunkelsten Farben geschildert wurden. Auf diese Weise bildete sich im Verlauf des 19. Jahrhunderts in Hispanoamerika zumindest in der Theorie ein klar umschrie-

33 28. September 1821 Mexiko. Ebd. 90.

34 2. Juli 1823 Nicaragua. Emilio Alvarez Lejarza (Hrsg.), Las constituciones de Nicaragua (Madrid 1958) 319.

35 Manuel de la Bárcena, Manifiesto al mundo. La justicia y la necesidad de la independencia de la Nueva España (1821), in: Jaime Olveda (Hrsg.), Los discursos opuestos sobre la independencia de la Nueva España (Madrid 2006) 108-127, hier $114 \mathrm{f}$.

Zur Differenz zwischen US-amerikanischer und hispanoamerikanischer, insbesondere argentinischer Unabhängigkeitserklärung s. Bonifacio del Carril, La declaración de la independencia (o. O. 1966). 
benes, wenngleich nicht so bezeichnetes Selbstbestimmungsrecht heraus. Das Recht auf Unabhängigkeit war nun nicht mehr negativ als Notrecht die Folge schlechter Behandlung des betreffenden Volkes durch ein anderes oder durch dessen Regierung, sondern positiv die Folge der Eigenschaft, ein Volk zu sein. Im Maße, als sich die Begründung für die Unabhängigkeit vom Unrecht der Gegenseite loslöst, kann auch von Selbstbestimmung gesprochen werden. Eine Unabhängigkeit hingegen, die zu gewähren dem Übeltäter als Strafe auferlegt wird und die damit gleichzeitig zur erlaubten Sezession wird, ist kein Resultat von Selbstbestimmung, sondern vielmehr von Fremdbestimmung, und hinter ihr steht auch kein wirkliches Selbstbestimmungsrecht, denn ein solches ist nur als absolutes, nicht als konditionales Recht denkbar.

Die Herausbildung des absoluten Rechts auf Unabhängigkeit ist Hispanoamerikas wichtigster Beitrag zur Entstehung des Konzepts des Selbstbestimmungsrechts der Völker. Das Konzept war damit Jahrzehnte vor dem einschlägigen Ausdruck entstanden, wobei dieser in Europa gebildet wurde und bis zum heutigen Tage keine Anwendung auf Amerika gefunden hat. Die Auffassung von einem uneingeschränkten Recht eines jeden Volkes (wie immer dieses definiert wird oder sich selbst definiert) auf Unabhängigkeit stand, wenngleich nicht terminologisch, so doch der Sache nach bereit. Und sie wurde nur in Amerika gebraucht - die Vorstellung, die Bevölkerung in anderen Kontinenten (auch in Europa) gelegener Territorien könne ein nichtkonditionales Recht auf Unabhängigkeit haben, war noch nicht denkbar.

\section{Die Bändigung der Anarchie: uti possidetis und Sezessionsverbot}

Das moderne Selbstbestimmungsrecht ist also nicht erst am Ende des Ersten Weltkrieges oder gar in der Entkolonisierung nach 1945 konzipiert worden, sondern zwischen 1776 und 1826, wobei das entscheidende Element, das nicht mehr konditionale, sondern uneingeschränkte Recht eines Volkes auf staatliche Eigenständigkeit seine volle Ausprägung erstmals und bis zum 20. Jahrhundert auch ausschließlich in Hispanoamerika fand. Das war, ob sie nun positiv oder negativ beurteilt wird, eine Pionierleistung ersten Ranges. Sie brachte indessen ein Element der Anarchie in das Völkerrecht, das die Stabilität der internationalen Ordnung gefährdete. Wenn jedes Volk, ja jede Gruppe, die sich selbst als Volk verstand, das Recht auf einen eigenen souveränen Staat hatte, dann war mit einer zunehmenden Zersplitterung der Staatenwelt zu rechnen. Ein erster wichtiger Vorbehalt wurde nicht explizit gemacht, ergab sich aber aus der Praxis: Das Selbstbestimmungsrecht blieb auf die Entkolonisierung begrenzt, und hier zunächst wieder auf europäische Siedlungskolonien. Das Recht auf Unabhängigkeit stand nur Völkern, oder Gesellschaften, oder sonstigen sich als zusammengehörig empfindenden Gruppen zu, die ausschließlich oder wenigstens überwiegend europäischer Ab- 
stammung waren und zugleich lediglich außerhalb Europas siedelten oder Gebietsherrschaft ausübten. Die Herrschaft in Übersee ging somit von den in Europa lebenden Europäern nicht an die schon vor ihnen außerhalb Europas siedelnden Völker, sondern an die europäischen oder europäischstämmigen, allenfalls noch an gemischte Bevölkerungen in Übersee.

Die Frage war, ob sich solche und ähnliche inhaltlich gesehen völlig willkürlichen Einschränkungen würden halten können. Weshalb sollte ein Volk, das von einem anderen durch einen Ozean oder durch einen oder mehrere andere Staaten getrennt war, ein Recht auf staatliche Unabhängigkeit haben, nicht aber ein solches, das von einem anderen nur durch einen Fluß oder eine Bergkette, oder gar nur durch eine gerade Linie im Gelände geschieden war? Und weshalb sollten europäische oder europäischstämmige oder vielleicht auch noch gemischte Bevölkerungen ein solches Recht haben, nicht aber alteingesessene? Erneut wurden die Probleme in Amerika gelöst, wobei diesmal Iberoamerika vorausging und Nordamerika lediglich einen kurzen Schlußstrich zog, der allerdings einem Paukenschlag gleichkam.

Selbst wenn man sich auf Entkolonisierung in Übersee beschränkte - sobald ein oder mehrere neue Staaten entstanden, stellte sich die Frage, wie die Grenzen gezogen werden sollten. Was in der Theorie wenig problematisch schien, konnte, ja mußte sich aber in der Praxis rasch als ausgesprochen verwickelt erweisen. Sollten für die Grenzziehung objektive oder subjektive Kriterien gelten oder eine Mischung aus beiden? Nahm man objektive Kriterien, etwa die Sprache oder die Religion, so konnte jedes Kriterium zu einer anderen Einteilung führen, und Konflikte waren programmiert. Dem stand das subjektive Kriterium der Wünsche der Betroffenen gegenüber. Versuchte man sich daran zu halten, mittels Volksabstimmungen, so stand keineswegs fest, daß dabei handhabbare und halbwegs vernünftig voneinander abgrenzbare Einheiten herauskamen. Dazu konnte sich der Wille der Betroffenen im Ablauf der Zeit immer wieder ändern.

Die Schwierigkeiten, Widersprüchlichkeiten und Ungereimtheiten lagen auf der Hand. Je konsequenter man versuchte, das Prinzip der Selbstbestimmung zu verwirklichen, desto inkonsequenter wurden die Ergebnisse. Lateinamerika war zum Zauberlehrling geworden. Im Gegensatz zu diesem fand es aber das rettende Wort, das zwar keine vollständige, aber doch relativ wirkungsvolle Abhilfe brachte, in der Form des sogenannten uti possidetis ${ }^{36}$. Es war eine ausgesprochen vage Figur aus dem römischen Recht, die lediglich „so, wie ihr besitzt“ bedeutete.

36 Zum uti possidetis vgl. Steven R. Ratner, Drawing a better line: uti possidetis and the borders of new states, in: The American Journal of International Law 90 (1996) 590-624. Christiane Simmler, Das uti possidetis-Prinzip: zur Grenzziehung zwischen neu entstandenen Staaten (Berlin 1999); Michael Weber, Uti possidetis juris als allgemeines Rechtsprinzip im Völkerrecht - Überlegungen zum Verhältnis von uti possidetis, Selbstbestimmungsrecht der Völker und Effektivitätsprinzip (Göttingen 1999); Frank Wooldridge, Uti possidetis doctrine. In: Encyclopaedia of Public International Law Bd. 4 (Amsterdam 2003) 1259-1262. Ein breiter Überblick vor allem für die jüngste Zeit bei: Olivier Corten u. a. (Hrsg.), Démembrements d'Etats et délimitations territoriales: l'uti possidetis en question(s) (Brüssel 1999). Eine umfassende historische Studie fehlt. 
$\mathrm{Zu}$ ergänzen ist die Formel durch ita possideatis, „so sollt ihr besitzen“. Gemeint ist die Festschreibung des status quo. Dieser wird in zwei Versionen aufgespalten: uti possidetis iuris und uti possidetis facto, den rechtlich (abgesicherten) und den faktischen Besitzstand. In der Regel galt unter hispanoamerikanischen Staaten der rechtliche Besitzstand, in ihrem Verkehr mit Portugal und später mit Brasilien der faktische. Der zentrale Inhalt des Prinzips besagte, daß die Grenzen der größeren spanischen Verwaltungseinheiten unverändert als Grenzen der unabhängigen Staaten übernommen werden sollten, ungeachtet der Zusammensetzung der Bevölkerung in der betreffenden Einheit. Die Abgrenzung der neuen Staaten voneinander erfolgte also nur zufällig gemäß den Wünschen der Betroffenen, weil auch die alten Verwaltungsgrenzen nur zufälligerweise mit den Wünschen der betroffenen Bevölkerungen übereingestimmt hatten.

In der besonders einflußreich gewordenen Formulierung, die 1922 in einem Schiedsspruch des Schweizer Bundesrats in einem Gebietskonflikt zwischen Kolumbien und Venezuela erfolgte, wurde das Prinzip wie folgt umrissen: „Als die spanischen Kolonien in Mittel- und Südamerika sich im zweiten Jahrzehnt des 19. Jahrhunderts unabhängig erklärten, nahmen sie ein staats- und völkerrechtliches Prinzip an, das sie ,uti possidetis von $1810^{\prime}$ nannten. Damit stellten sie fest, daß die Grenzen der neugegründeten Republiken die Grenzen der spanischen Provinzen seien, an deren Stelle sie sich setzten. Dieses allgemeine Prinzip hatte den Vorteil, daß es die uneingeschränkte Regel aufstellte, daß es, rechtlich gesehen, im ehemaligen Spanisch-Amerika keine herrenlosen Gebiete gibt. Obwohl zahlreiche Gegenden von den Spaniern nicht besetzt worden waren und zahlreiche unerforschte oder von nicht zivilisierten Eingeborenen bewohnte Gegenden existierten, wurden diese Gegenden als rechtens zur jeweiligen Republik gehörend betrachtet, die die Nachfolge derjenigen spanischen Provinz angetreten hatte, zu der diese Gebiete aufgrund der alten königlichen Erlasse des spanischen Mutterlandes gehört hatten. Obwohl diese Gebiete de facto nicht okkupiert waren, wurden sie im allgemeinen Einvernehmen als von der neuen Republik von der ersten Stunde an de jure okkupiert betrachtet. Übergriffe und unzeitige Kolonisationsversuche von der anderen Seite der Grenze, ebenso wie de facto-Okkupationen wurden gegenstandslos oder hatten keine Rechtsfolgen. Man hoffte auch, daß dieses Prinzip den Vorteil haben würde, Grenzstreitigkeiten zwischen den neuen Staaten zu unterbinden. Schließlich schloß dieses Prinzip mögliche Festsetzungsversuche europäischer Kolonialmächte in Gebieten aus, die sie herrenlos hätten erklären können. Die völkerrechtliche Situation Spanisch-Amerikas war von Anfang an gänzlich anders als etwa die Afrikas. Dieses Prinzip erhielt später eine allgemeine Bestätigung unter dem Namen der Monroedoktrin, aber es war seit langem die Grundlage des südamerikanischen öffentlichen Rechts." ${ }^{37}$

Die Umsetzung des Prinzips in durchsetzbare und früher oder später international anerkannte Grenzen war oft umstritten. Davon zeugen zahlreiche Grenz-

37 24. März 1922 Schiedsspruch des Schweizer Bundesrates zwischen Kolumbien und Venezuela, in: Reports of International Arbitral Awards Bd. 1 (New York 1948) 227-290, hier 228. 
konflikte, die teilweise bis in die Gegenwart hinein andauern ${ }^{38}$. Mit dem uti possidetis war also kein Universalmittel für die Lösung von Grenzstreitigkeiten gefunden worden - deren Beilegung war letztlich eine Frage des politischen Willens, der Bereitschaft zur Konfliktlösung. Die Grenzziehung in der Natur bereitete oft große Schwierigkeiten, hatte die spanische Verwaltung doch viele Grenzen, insbesondere zwischen den eigenen Besitzungen, oft nur auf dem Papier gezogen, zumal dann, wenn sie die Gebiete ohnehin nicht wirklich beherrscht hatte.

Entscheidend aber war das Prinzip. Wie immer es im einzelnen gehandhabt wurde, das uti possidetis bedeutete den Übergang von einem inhaltlichen zu einem formalen Kriterium für die Grenzfestlegung. Inhaltlich war ein Kriterium, wenn es vom subjektiven Zugehörigkeitswunsch der Betroffenen ausging oder von deren objektiver Zugehörigkeit zu einer bestimmten Religion, Sprachgemeinschaft oder Rasse oder von irgendeinem sonstigen Merkmal oder auch einer Gruppe von Merkmalen - der Anspruch war stets, daß die getroffene Lösung objektiv oder subjektiv etwas mit der Konstituierung einer sich selbst bestimmenden Einheit zu tun hatte. Und diese Einheit war nicht einfach zufällig zustandegekommen, sondern ergab sich aus den aktuellen, konkreten Verhältnissen heraus, auch wenn dabei noch so große Kompromisse zu schließen waren. Die Zuordnung zu einer selbstbestimmten Einheit mußte in irgendeiner Weise inhaltlich begründet werden, so unglaubwürdig die Begründung dann auch sein mochte. Ein formales Kriterium hatte demgegenüber mit der Frage, um die es ging, nämlich der Bildung selbstbestimmter Einheiten, nichts zu tun. Als spanische Kolonialbeamte im 16.18. Jahrhundert interne Verwaltungsgrenzen gezogen hatten, hatten sie nicht die Absicht gehabt, selbstbestimmte Einheiten voneinander abzuscheiden, sondern nur an verwaltungstechnisch handhabbare Territorien gedacht. Ihre Grenzziehungen erfolgten unabhängig von selbstbestimmungsrelevanten subjektiven Wünschen und objektiven Merkmalen der betroffenen Individuen.

Genau darin lag der große Vorteil des uti possidetis, freilich nur, solange man es nicht unter dem Gesichtspunkt einer möglichen Selbstbestimmung betrachtete, sondern unter demjenigen möglichst großer Stabilität. Mit Selbstbestimmung hatte es nicht das geringste zu tun; es widersprach ihr sogar entschieden. Hier lag denn auch das Problem, ja der immanente Widerspruch der Methode. Die Einführung des Selbstbestimmungsrechts, unabhängig von der Frage, ob der Ausdruck schon existierte und verwendet wurde, drohte die Welt (vorläufig ging es freilich nur um Amerika) ins Chaos zu stürzen. Wollte man dies verhindern, so mußte eine Einschränkung von außerhalb erfolgen. Das war die Funktion des uti possidetis. Ihm haftete etwas von einer Entscheidung durch das Los an - eine inhaltliche Entscheidung hätte zu endlosem Streit geführt.

Philosophisch betrachtet bestand bei den spanischen Grenzziehungen in Amerika (und später auch bei anderen kolonialen Grenzziehungen durch die Europäer) eine Analogie zum vor allem von John Rawls eingeführten Konzept einer

38 Vgl. etwa Jorge I. Dominguez, Conflictos territoriales y democracia en América Latina (Buenos Aires 2003). 
„originären Situation“ (original position), gekennzeichnet durch den für den Entscheidenden bestehenden „Schleier der Unwissenheit“ (veil of ignorance). Die Beamten konnten nicht wissen, zu wessen Gunsten sich ihre Grenzziehungen künftig einmal auswirken würden. Und als häufig versetzte Funktionäre wußten sie auch nicht, auf welcher Seite der von ihnen gezogenen Grenze sie einmal leben und arbeiten würden 39 .

Freilich waren damit noch nicht alle Probleme gelöst, die durch die Einführung oder auch nur Postulierung des Selbstbestimmungsrechts entstanden waren. Das uti possidetis entschied nur darüber, welche bestehenden (Verwaltungs- und Staats-)Grenzen zu Grenzen unabhängiger Staaten werden konnten. Es bestimmte aber nicht, welche der möglichen Grenzen zu wirklichen wurden. Dadurch blieb zunächst offen, wieviele Staaten mit welchen Grenzen in den Kolonien entstehen würden und damit wiederum, wie groß sie würden. In Nordamerika gelang es nicht nur, alle vormals britischen Besitzungen (mit Ausnahme des Sonderfalles Kanada) zusammmenzuhalten, sondern auch, sie enorm auszuweiten. Dasselbe galt für die portugiesischen Besitzungen in Brasilien, nicht aber für Hispanoamerika.

Das Problem ließ sich nicht einfach mit dem Federstrich des uti possidetis lösen. Ging man davon aus, daß Selbstbestimmung nur als Entkolonisierung möglich war (was eine willkürliche Setzung bedeutete), dann war zwar die Sache in der Tat mit der Festlegung der Kolonialgrenzen als neuen Staatsgrenzen gemäß uti possidetis erledigt. Die Tatsache aber, daß viele Kolonialgrenzen gerade nicht zu Staatsgrenzen wurden (sonst wäre es zu einer weitreichenden Zersplitterung des Kontinents gekommen), mußte Versuche begünstigen, die zunächst einmal geschaffenen neuen Staaten weiter aufzugliedern, durch Sezession, ob diese nun erzwungen oder durch gütliche Einigung erfolgen würde. Gruppen, die sich als Volk verstanden, bislang aber über keinen eigenen Staat verfügt hatten, würden einen solchen für sich verlangen. Das Korrelat zu jeder uneingeschränkten Ausübung von Selbstbestimmung ist, zumindest der Möglichkeit nach, die Sezession. Wer einmal ein bestimmtes Gebiet unter Berufung auf Selbstbestimmungskriterien oder auch nur durch die Anwendung eines Formalkriteriums aufteilt, der signalisiert damit die Möglichkeit einer weiteren Aufteilung. Inhaltlich gesehen kann man territorialen Untereinheiten, die durch Ausübung von Selbstbestimmung oder auch nur durch Anwendung des uti possidetis entstanden sind, schlecht eine weitere Aufgliederung verbieten. Der Preis für die Selbstbestimmung kann eine weitere, schließlich fast bis ins Unendliche fortschreitende Zersplitterung sein.

39 John Rawls, A theory of justice (London 1972) 17-22; 136-142 und passim. 


\section{Die USA und das Sezessionsverbot}

Hier schlugen die Verhältnisse innerhalb Amerikas in der Mitte des 19. Jahrhunderts um. Zunächst waren die USA im Vorteil, da es ihnen gelang, die ehemals britischen Territorien, die sich 1776 zusammengeschlossen hatten, nicht nur zusammenzuhalten, sondern den entstandenen Staat auch sehr stark auszuweiten. Das war zwar oft mit neuen Schwierigkeiten verbunden. Immer wieder bildeten sich in den USA Bewegungen, die die Sezession als Ziel verfolgten, insbesondere im Zusammenhang der Beibehaltung wie auch der Abschaffung der Sklaverei ${ }^{40}$. Doch zunächst hatten sie kaum ernsthafte Erfolgschancen - bis sich die Lage 1860/1861 zuspitzte und zur Sezession der Südstaaten führte. Dadurch wurde in zunehmendem Maße die Sklaverei zum Streitgegenstand. Der entscheidende Punkt aber war die Frage des Sezessionsrechts, das vom Süden beansprucht und vom Norden bestritten wurde. Der Sezessionsversuch des Südens wurde im Bürgerkrieg 1861-1865 in Strömen von Blut erstickt. Allerdings nur in einem Bürgerkrieg, nicht in einem Staatenkrieg. Man konnte also nicht sagen, die USA hätten ein völkerrechtliches Sezessionsverbot durchgesetzt. Es war lediglich ein staatsrechtliches Verbot. Dennoch war die Wirkung weit über die USA hinaus angesichts von deren rasch wachsender weltpolitischen Bedeutung und angesichts der globalen Auswirkungen des Bürgerkrieges groß. Das traf ganz besonders für Amerika zu, wo fortan praktisch ein Sezessionsverbot galt. Bis 1860/1861 war es in Iberoamerika durchaus hin und wieder zu Sezessionen oder zu einvernehmlichen Auflösungen von Staaten gekommen. So löste sich 1830 Großkolumbien in Kolumbien, Venezuela und Ecuador auf. Die Dominikanische Republik sagte sich 1844 erfolgreich von Haiti los. Die zentralamerikanischen Provinzen schlossen sich 1821 Mexiko an und lösten sich 1823 größtenteils wieder von ihm, unter dem Namen der Vereinigten Provinzen von Zentralamerika, bis sich der neue Staat nach einem Bürgerkrieg 1838-1841 in fünf selbständige Staaten auflöste. Die Selbstbestimmung war damit wirksamer als bisher auf einen einmaligen Akt der Entkolonisierung reduziert worden. Das gilt für die USA bis heute, ist hingegen nicht zu wirklich allgemein geltendem Völkerrecht geworden. Dazu trugen die USA selber bei, als sie 1903 die Sezession Panamas von Kolumbien unterstützten und teilweise inszenierten ${ }^{41}$. Unter dem Gesichtspunkt des von den USA sonst favorisierten Sezessionsverbots war die Lage klar: Panama hatte kein Recht, sich von Kolumbien zu lösen, auch wenn seit der Unabhängigkeit in Panama immer wieder Sezessionspläne geschmiedet worden waren. Die Frage, ob die Bevölke-

$40 \mathrm{Vgl}$. Mark E. Brandon, Free in the world. American slavery and constitutional failure (Princeton 1998) u. ders., Secession, constitutionalism, and American experience, in: Stephen Macedo, Allen Buchanan (Hrsg.), Secession and self-determination (New York 2003) 272314.

41 Zur reichen Literatur über die Sezession von Panama vgl. Thomas Fischer, Panamas „Unabhängigkeit“. Ein historiographischer Überblick, in: Rüdiger Zoller (Hrsg.), Panama: 100 Jahre Unabhängigkeit. Handlungsspielräume und Transformationsprozesse einer Kanalrepublik (Erlangen 2004) 23-50. 
rung von Panama eine Sezession wollte, war irrelevant - sie hatte für die Festlegung von Grenzen unabhängiger Staaten in ganz Amerika nie eine entscheidende Rolle gespielt. Für die USA aber bedeutete eine Sezession Panamas die Möglichkeit einer stärkeren Einflußnahme auf den Kanalbau, letztlich sogar die Kontrolle des Kanals, die dann auch auf Jahrzehnte hinaus erlangt wurde. Es war indessen vor wie nach dieser Episode völlig undenkbar, daß die USA ein Recht der Gliedstaaten auf Austritt aus der Union in ihre Verfassung aufgenommen hätten.

Der US-Bürgerkrieg machte besonders deutlich, daß sich die Beschränkung des Selbstbestimmungsrechts auf die Entkolonisierung keineswegs zwingend aus dem normalen Verständnis von Selbstbestimmung ergab. Der treibende Kopf bei der rigorosen und blutigen Durchsetzung des Sezessionsverbots für die Vereinigten Staaten war Präsident Lincoln. Noch wenige Jahre vor dem Krieg hatte er ein freies Sezessionsrecht für die US-Einzelstaaten, ja für beliebige Bestandteile eines Staates gerechtfertigt. Im Zusammenhang des Krieges gegen Mexiko meinte er am 12. Januar 1848 im Repräsentantenhaus: „Jedes Volk an jedem Ort, das den Wunsch hat und über die nötige Macht verfügt, hat das Recht, sich zu erheben und sich der bestehenden Regierung zu entledigen und eine neue zu bilden, die ihm besser paßt. Das ist ein höchst wertvolles, ja ein höchst geheiligtes Recht, ein Recht, von dem wir hoffen und glauben, daß es die Welt befreien wird. Dieses Recht ist auch nicht auf Fälle beschränkt, in denen das ganze Volk eines bestehenden Staates [government] es ausüben möchte. Jeder Teil eines solchen Volkes, der kann, darf sich befreien [revolutionize] und aus dem von ihm bewohnten Gebiet einen eigenen Staat bilden [and make their own]. Mehr noch: Jede Mebrheit irgendeines Teils eines solchen Volkes kann eine Revolution durchführen, indem sie eine Minderheit unterwirft, die mit ihr vermischt oder in ihrer Nähe lebt und sich ihrer Bewegung widersetzt." Die US-Amerikaner seien genau so mit den Anhängern des Königs in ihrer eigenen Revolution umgegangen ${ }^{42}$.

Radikaler kann ein Sezessionsrecht kaum formuliert werden, und es ist wenig wahrscheinlich, daß Lincoln diese Rede schon 1861 oder auch 1865 vergessen hatte. Er war von der Sache her dem umfassenden Begriff des Selbstbestimmungsrechts, ohne den Ausdruck zu kennen, schon sehr viel näher gekommen als die Europäer.

\section{Amerikanisches und europäisches Selbstbestimmungsrecht}

Damit waren bis zum Jahr 1865 in Amerika die entscheidenden Grundlagen für das moderne Selbstbestimmungsrecht gelegt worden, im positiven wie im negativen, im einschränkenden wie im erweiternden Sinne. Nach wie vor existierte dafür

42 Abrabam Lincoln, The collected works, Bd. 1, hrsg. v. Roy P. Basler (New Brunswick 1953) 431-442, hier 438. 
unter den Akteuren kein das ganze Phänomen erfassender Begriff. In Europa hingegen war inzwischen von Selbstbestimmung und Selbstbestimmungsrecht der Völker die Rede. Auffällig ist, daß Europa in der Sache (nicht aber in der Terminologie) viel, ja das meiste von Amerika übernommen hat, während Amerika seine eigene Tradition beibehalten und den Ausdruck wohl deshalb bewußt nicht übernommen hat.

Die entscheidenden Elemente für das in Amerika herausgebildete Selbstbestimmungsrecht und vor allem für dessen Begrenzung waren, in der Abfolge ihres Aufkommens: Beschränkung auf Entkolonisierung, Grenzziehung mittels Formalkriterium (uti possidetis) statt durch Plebiszit, oder anhand objektiver Kriterien, sowie Sezessionsverbot außerhalb des Rahmens der Entkolonisierung. Die ersten beiden Elemente konnten seit 1865 als Bestandteile des amerikanischen Völkerrechts betrachtet werden, nicht jedoch das Sezessionsverbot, das in Panama 1903 ostentativ durchbrochen wurde.

Bei systematischer statt chronologischer Betrachtung gehören das erste und das dritte Element zusammen. Durch die Beschränkung des Selbstbestimmungsrechts auf die Entkolonisierung wird seine Ausübung zu einem einmaligen Akt. Grundprinzip ist dabei das Sezessionsverbot. Würde ein solches uneingeschränkt und zu jeder Zeit gelten, so könnte gar nicht von Selbstbestimmung und Selbstbestimmungsrecht gesprochen werden, solange beides nicht einfach als Festschreibung des status quo definiert würde. Indem Entkolonisierung erlaubt (und zuweilen sogar geboten) wird, wird das Sezessionsverbot durchbrochen, aber nur einmalig, sofern davon ausgegangen werden kann, daß Entkolonisierung nicht zu einer neuen kolonialen Situation führt, daß also die Entkolonisierung nicht Staaten entstehen läßt, die noch immer oder erneut aus Teilen bestehen, die durch einen Ozean oder eine Landmasse oder beides voneinander getrennt sind.

Die genannten Einschränkungen und Spezifizierungen bezogen sich im 19. Jahrhundert nur auf Amerika. Genauer betrachtet galten sie sogar, mit der Ausnahme von Saint Domingue/Haiti, nur für europäische Siedlungskolonien in Amerika; auf keinen Fall galten sie für von europäischen Staaten beherrschte Gebiete in anderen Erdteilen, insbesondere in Afrika, sofern es sich dabei nicht um Siedlungskolonien von Europäischstämmigen oder Mischlingen handelte. Für eine Weiterentwicklung des Selbstbestimmungsrechts oder auch nur für seine erneute Anwendung nach der Unabhängigkeit der amerikanischen Staaten bestand also keine Gelegenheit. Das galt, für das so definierte Selbstbestimmungsrecht, mit kleineren Ausnahmen bis nach dem Zweiten Weltkrieg. Freilich nur, wenn man sich genau an das amerikanische Vorbild hielt. Das war nicht der Fall und zeigte sich nicht zuletzt in der Entstehung des Begriffs ,Selbstbestimmungsrecht ${ }^{\star}$ nach der Mitte des 19. Jahrhunderts innerhalb Europas. Dabei wird ein Grund dafür sichtbar, daß die Vorgänge in Europa eine andere Bezeichnung erhielten als in Amerika und daß Amerika, selbst nachdem der prägnante Ausdruck des Selbstbestimmungsrechts der Völker geläufig geworden war, ihn nicht aufgriff für die Bezeichnung der eigenen Tradition. In Europa war nirgends eine Entkolonisierung im hier definierten Sinne möglich, weil die Herrschaftsgebiete eines Staates in aller 
Regel miteinander zusammenhingen oder wenigstens nur geringe Zwischenräume aufwiesen. Also konnten die Selbstbestimmung und das Selbstbestimmungsrecht auch nicht auf Entkolonisierung beschränkt werden, wenn man denn überhaupt von solchen Vorgängen sprechen wollte. Sonst waren die beiden Begriffe gar nicht anwendbar auf Europa. Das bedeutete für das Sezessionsverbot, daß es keine klaren Grenzen kannte. Entweder es wurde strikt eingehalten - dann war jegliche Sezession außerhalb des kolonialen Zusammenhangs ausgeschlossen, und von Selbstbestimmung konnte nicht die Rede sein, oder aber die Sezession wurde grundsätzlich erlaubt - dann mußte mit beliebiger Aufspaltung bestehender Staaten gerechnet werden. Ähnliches galt für das Formalkriterium für die Abgrenzung neuer Staaten. Wenn nach Auffassung der Beteiligten eine Entkolonisierung erfolgte, dann bot sich die Übernahme der Kolonialgrenzen an. Konnte man nicht von Kolonien sprechen, so fiel es schwer, ein anderes Formalkriterium zu finden. Erst im späten 20. Jahrhundert wurde ein teilweiser Ersatz in der Gestalt von Verwaltungsgrenzen innerhalb europäischer Staaten gefunden.

Die Folgen der unterschiedlichen Voraussetzungen für das Selbstbestimmungsrecht in Amerika einerseits und in den übrigen Kontinenten andererseits waren beträchtlich. Das in Amerika entwickelte Selbstbestimmungsrecht hatte in Europa andere, begrenztere Wirkungen, weil nicht von Entkolonisierung die Rede sein konnte - letztlich scheiterte es hier sogar. Es gelang nicht, mit seiner Hilfe in Europa eine stabile Staatenordnung zu errichten, wie sich insbesondere nach den beiden Weltkriegen zeigte. In Amerika war durch die drei Prinzipien ein realistisches Ziel vorgegeben, auch, ja gerade weil sie einander widersprachen. Wenn es zu Auseinandersetzungen und sogar zu Kämpfen kam, dann ging es um die Verwirklichung der Entkolonisierung, des uti possidetis und, in der Regel jedenfalls, des Sezessionsverbots. Umstritten war dabei die Durchführung, nicht das Prinzip, also etwa der Verlauf einer Grenze oder die Modalitäten einer Entkolonisierung, nicht das grundsätzliche Recht und später sogar die Pflicht dazu. In Europa hingegen konnten die Neuordnungen nach beiden Weltkriegen nicht auf solche Prinzipien reduziert werden. Von Entkolonisierung konnte weder 1919 noch 1945 die Rede sein; die Grenzziehungen hatten erst in den Jahren seit 1989 teilweise etwas mit dem uti possidetis zu tun, und von einem generell geltenden Sezessionsverbot kann bis in die Gegenwart nicht die Rede sein. Besonders deutlich wird das etwa in der Gegenüberstellung von Panama, das 1903 in Amerika einen Sonderfall bildete, und Kosovo, das 2008 am Ende einer ganzen Reihe von Sezessionen in Europa stand.

Das in Amerika entwickelte Selbstbestimmungskonzept mußte in Europa scheitern, weil die in Amerika gegebenen Voraussetzungen nicht erfüllt waren: Innerhalb Europas bestanden keine Kolonien im hier definierten Sinne; ein uti possidetis war nicht anwendbar, weil die Grenzen nicht Resultat einmaliger Akte einer Kolonialverwaltung waren, sondern in fast jedem Kilometer Resultat einer komplizierten Geschichte, und weil schließlich die Zurückweisung eines Rechts auf Sezession angesichts von Gruppen, die schon lange eine beträchtliche Eigenständigkeit zeigten, sehr viel schwerer fiel als bei vergleichsweise jungen Völkern. 
All dies galt primär für den Kontrast zwischen Europa und Amerika. Im Vergleich Amerikas mit Afrika und Asien war der Kontrast weniger stark und bei der Entkolonisierung sogar inexistent.

Am Ende des Zweiten Weltkrieges wurde das Selbstbestimmungsrecht als mögliches Prinzip der europäischen Staatenordnung sogar bewußt aufgegeben und teilweise durch ein ganz anderes Prinzip ersetzt: Die Staaten wurden dabei nicht der Bevölkerung angepaßt, sondern man paßte die Bevölkerung den Staaten beziehungsweise deren Grenzen an. Man zog also zunächst die Grenzen, die sich als Folgen des Krieges und damit der Machtverhältnisse ergeben hatten und nahm danach Umsiedlungen vor, um die (in der Regel von der Sprache ausgehende) Einteilung der Bevölkerung dem anzupassen. Nun konnte man auch von den in Amerika entwickelten drei Kriterien nicht behaupten, sie stellten die Verwirklichung der Selbstbestimmung dar. Sie ließen sich vielmehr nur deshalb handhaben, weil sie gerade nichts mit Selbstbestimmung zu tun hatten und statt dessen deren anarchische Konsequenzen eindämmten. In Europa aber hatte die neue Methode nicht nur nichts mit Selbstbestimmung zu tun, sondern es handelte sich ganz klar um deren Gegenteil, um Fremdbestimmung.

Der Zweite Weltkrieg führte also zum Ende dessen, was in Europa seit der Mitte des 19. Jahrhunderts zunehmend als Selbstbestimmung und als Selbstbestimmungsrecht bezeichnet wurde. Anders die amerikanische Tradition, die nun mit der europäischen Terminologie verbunden wurde und mit ihr große Erfolge feierte. Amerika stellte ein praktikables Verfahren zur Verfügung, das sich weitgehend unverändert übernehmen ließ, während Europa mit dem Selbstbestimmungsrecht der Völker das zündende Schlagwort lieferte, das schließlich 1966 sogar weltweit als oberstes Menschenrecht kodifiziert wurde.

In den zentralen Punkten bestand Übereinstimmung zwischen der ersten und der zweiten Entkolonisierung, auch wenn in einer nicht auf die Selbstbestimmung bezogenen Frage ein wichtiger Unterschied bestand: Erst nach 1945 erfolgte eine Universalisierung in dem Sinne, daß das Kriterium für die Entkolonisierung nur noch die räumliche Distanz, nicht mehr die Hautfarbe, die Abstammung oder die Sprache etc. war. Anspruch auf Entkolonisierung hatten also nicht mehr nur europäische Siedlungskolonien, sondern alle über eine größere Distanz hinweg beherrschten Gebiete und Völker. Es kam sogar sehr rasch zu einer Umkehrung: als illegitim und ohne Anspruch auf ein Selbstbestimmungsrecht galten nun europäische Siedlungskolonien in Übersee, während alle von Europäern in Übersee beherrschten Gesellschaften, die überwiegend aus Eingesessenen bestanden, nun einen zwingenden Anspruch auf Unabhängigkeit hatten.

Die Übereinstimmung der zweiten mit der ersten, amerikanischen Phase der Entkolonisierung zeigte sich in allen drei zentralen Kriterien. Am deutlichsten war sie in der Entkolonisierung. Diese war nach Auffassung vieler Führer der Dritten Welt, und sie war vor allem faktisch ein einmaliger Akt. Nach diesem kam eine weitere Aufsplitterung ebensowenig in Frage wie die Loslösung von US-Einzelstaaten von der Union zur Debatte stand - das Sezessionsverbot war selbstverständlich. Die Abgrenzung der neugebildeten Staaten erfolgte gemäß uti posside- 
tis, wenngleich dieser Fachausdruck nur selten verwendet wurde. Insbesondere in Afrika wurde die Heiligkeit der Kolonialgrenzen zur Grundlage der internationalen Beziehungen schlechthin, nicht etwa obwohl, sondern weil die ethnischen, sprachlichen und sonstigen Verhältnisse so kompliziert waren. Es ist bezeichnend, daß gerade in Afrika immer wieder der Ruf nach gerechten oder angemessenen Grenzen ertönt, daß aber niemand ernsthaft glaubt, daß es möglich sein könnte, einen allgemein akzeptierbaren Vorschlag für eine Neuordnung zu machen.

Natürlich setzte sich das amerikanische Vorbild nicht uneingeschränkt durch, so wie die herausgebildeten Grundsätze ja auch in Amerika verletzt wurden, insbesondere bei der Sezession Panamas. Dennoch konnte man von einer Universalisierung des amerikanischen Modells sprechen. Nach wie vor hatte hingegen Amerika für die eigene Tradition die europäische Terminologie nicht übernommen, obwohl sie ohne jeden Zweifel viel zugkräftiger war. ,Unabhängigkeit wurde nicht durch Selbstbestimmung und Selbstbestimmungsrecht ersetzt. Auf der anderen Seite war die Durchsetzung der Selbstbestimmungsprinzipien in Europa anders als in Amerika und später in der Dritten Welt gescheitert. Das mochte zu Zurückhaltung bei der Übernahme der Terminologie geführt haben. Durch die Übernahme der Selbstbestimmungsterminologie für ihre eigene Tradition hätten die Amerikaner diese Tradition tendenziell entwertet.

Voraussetzung für die Durchführung dessen, was man als amerikanisches Modell des Selbstbestimmungsrechts bezeichnen könnte, war das Vorhandensein von Gebieten mit kolonialer Situation. Ohne Entkolonisierung keine Selbstbestimmung in amerikanischer Manier. Doch die Selbstbestimmung und das Selbstbestimmungsrecht waren inzwischen in den Rang universaler Prinzipien erhoben worden. Sie galten laut den Menschenrechtspakten von 1966 für alle Völker, nicht nur für alle Kolonialvölker. Man konnte die Selbstbestimmungsformel nicht einfach aus dem Verkehr ziehen. So setzte nach dem Ende der Entkolonisierung der Versuch ein, das amerikanische Modell den neuen Gegebenheiten anzupassen. Am leichtesten fiel die Anpassung des uti possidetis: An die Stelle der überseeischen Kolonialgrenzen bei der Auflösung der Kolonialreiche traten die internen Verwaltungsgrenzen bei der Auflösung von Föderationen: in der Sowjetunion, in Jugoslawien und in der Tschechoslowakei. Auch sonst lassen sich die Grundprinzipien des amerikanischen Modells relativ leicht anpassen, während bei der Durchführung im einzelnen größere Schwierigkeiten entstehen. An die Stelle des ersten Prinzips, der Entkolonisierung, ist die Auflösung von föderalistisch aufgebauten Staaten getreten. Welche Staaten aber gelten als föderalistisch aufgebaut und damit, unter Verzicht auf das Sezessionsverbot, als rechtmäßigerweise auflösbar? Es fällt leichter zu bestimmen, welche Staatsteile geographisch deutlich voneinander getrennt sind, als zwischen Föderationen und Nichtföderationen zu unterscheiden. Die Wahrscheinlichkeit, daß schließlich jeder Staat als seinen inneren Verwaltungsgrenzen entlang auflösbar gilt, ist groß. Dasselbe gilt für die fortschreitende Auflösung eines Staates in immer kleinere Bestandteile. Das ist besonders deutlich geworden in Kosovo, das keine jugoslawische Republik war, sondern Teil einer solchen und trotzdem unabhängig wurde. Es gilt auch in der ehe- 
maligen Sowjetunion, in der Territorien, die lediglich Teile früherer Sowjetrepubliken sind, Unabhängigkeit für sich beanspruchen, etwa Tschetschenien, Südossetien, Abchasien, Transnistrien oder Tatarstan.

Die Gefahren, die mit dieser Anpassung des in Amerika entwickelten Konzepts verbunden sind, liegen auf der Hand. Das Grundproblem hat sich nicht verändert: Selbstbestimmung und das Selbstbestimmungsrecht bilden ein anarchisches Prinzip, das, soll es nicht die Staatenordnung zerstören, gebändigt werden muß. Amerika hat für die Bewältigung des Problems, und damit für die Bändigung der Anarchie, ein ungewöhnlich erfolgreiches Modell entwickelt. Es verbindet das uneingeschränkte, absolute Recht auf Unabhängigkeit mit drei harten Einschränkungen, die das Recht handhabbar machen: Entkolonisierung, uti possidetis und Sezessionsverbot. Kernstück ist die Entkolonisierung, die aber seit den 1980er Jahren abgeschlossen ist. Das hat eine Anpassung erforderlich gemacht, die ihrerseits keineswegs abgeschlossen ist. Feststehen dürfte aber, daß eine erfolgreiche Lösung nur mit dem - wenn auch abgewandelten - amerikanischen Modell möglich ist; das europäische Modell ist spätestens im Zweiten Weltkrieg gescheitert. Die Chancen für das amerikanische Modell, das primär ein hispanoamerikanisches ist, stehen wesentlich besser. Sie sind allerdings durch die Übernahme der europäischen Tradition in der Form der Selbstbestimmungsterminologie wieder gemindert worden. In der Kodifikation von 1966 hat sich die uneingeschränkte Rede vom Selbstbestimmungsrecht aller Völker durchgesetzt. Die drei Einschränkungen Entkolonisierung, uti possidetis und Sezessionsverbot sind dabei nicht erwähnt worden. Sie nachträglich rechtsgültig einzuführen und durchzusetzen, würde schwer fallen und wäre unpopulär.

\section{Summary}

Today's right of self-determination is based on the sovereignty of the people. The first state to be built upon it was the United States. But its main foundation was the traditional right of resistance against an unjust ruler. The right to self-determination, however, belongs to a people not because it has been maltreated but just because it is a people. This doctrine was developed not by the US Declaration of Independence but by the Hispano-American declarations during the first decades of the $19^{\text {th }}$ century. This far-reaching right threatens the international order by allowing each group which considers itself as a people to found an independent, sovereign state. In order to contain such anarchical consequences three mechanisms were developed in America:

1. The right to self-determination was reduced to cases of decolonisation and restricted to European settlers and their offspring.

2. The borders of new states were drawn neither along ethnic, linguistic or other objective lines nor according to the results of plebiscites but strictly followed the lines drawn in earlier times by European colonial powers. This was the doctrine of uti possidetis, developed in Hispano-America. 
3. Once decolonisation had been achieved, there was a strict prohibition of secession, especially after it had been entrenched by the American Civil War.

The three principles were incompatible with the central idea of the people's right to self-determination, as they were much more restrictive. But they allowed to maintain international stability, which was far greater in America than in Europe where there was neither decolonisation nor uti possidetis. Only in the late $20^{\text {th }}$ century an analogy was constructed between the dissolution of federations (USSR and Yugoslavia) and decolonisation. 